\title{
Development of an airline revenue capability model for aircraft design
}

DOI:

10.2514/6.2010-9059

Link to publication record in Manchester Research Explorer

\section{Citation for published version (APA):}

Sutcliffe, P., \& Hollingsworth, P. (2010). Development of an airline revenue capability model for aircraft design. In 10th AIAA Aviation Technology, Integration and Operations Conference 2010, ATIO 2010/10th AIAA Avia. Tech., Int. and Oper. Conf. 2010, ATIO 2010 (Vol. 1). American Institute of Aeronautics and Astronautics . https://doi.org/10.2514/6.2010-9059

Published in:

10th AIAA Aviation Technology, Integration and Operations Conference 2010, ATIO 2010|10th AIAA Avia. Tech., Int. and Oper. Conf. 2010, ATIO 2010

\section{Citing this paper}

Please note that where the full-text provided on Manchester Research Explorer is the Author Accepted Manuscript or Proof version this may differ from the final Published version. If citing, it is advised that you check and use the publisher's definitive version.

\section{General rights}

Copyright and moral rights for the publications made accessible in the Research Explorer are retained by the authors and/or other copyright owners and it is a condition of accessing publications that users recognise and abide by the legal requirements associated with these rights.

\section{Takedown policy}

If you believe that this document breaches copyright please refer to the University of Manchester's Takedown Procedures [http://man.ac.uk/04Y6Bo] or contact uml.scholarlycommunications@manchester.ac.uk providing relevant details, so we can investigate your claim.

\section{OPEN ACCESS}




\title{
Development of an Airline Revenue Capability Model for Aircraft Design
}

\author{
Peter Sutcliffe* and Peter Hollingsworth ${ }^{\dagger}$ \\ The University of Manchester, Sackville Street, Manchester, M13 9PL, UK
}

\begin{abstract}
Typically value based approaches to the design of civil and commercial aircraft, be they net present value, surplus value, or any other utility based approach focus solely on the difference in cost between the alternatives, neglecting changes in revenue which might occur between the two concepts. Alternatively, if they do have a revenue focus, it is based upon simple relationships between payload capacity and revenue, assuming a either a fixed profit margin or fixed yield. This approach works well when comparing two similar or closely related concepts, but falls apart when investigating more radically different systems, e.g. a cruise efficient short take-off and landing concept. By using a value based approach it is relatively simple to structure a decision model to incorporate changing revenue capability. However, the ability to investigate differences in design is very much dependent upon the revenue model and assumptions that are made. If the revenue elasticity is the same for the two concepts then there is no benefit in using a variable revenue approach. However, in the cases where the elasticity is different, the revenue approach offers the potential to more properly investigate some fundamentally different alternative concepts.
\end{abstract}

\section{Nomenclature}

$\begin{array}{ll}\mathrm{C} & \text { Cost } \\ \mathrm{d} & \text { demand } \\ \text { Disc } & \text { Discount Multiplier } \\ \mathrm{E} & \text { Elasticity } \\ \mathrm{LF} & \text { Load Factor } \\ \mathrm{P}, \mathrm{p} & \text { price } \\ \mathrm{SV} & \text { Surplus Value } \\ \mathrm{R} & \text { Revenue } \\ \mathrm{t} & \text { Time, Project life } \\ \mathrm{U} & \text { Utility, Utilization } \\ \sigma & \text { Discount rate }\end{array}$

\section{Introduction}

There has been an increasing interest in using 'value' based approaches in all stages of the aerospace design process. This includes both commercial aircraft and government and military programs. ${ }^{1-6}$ The benefit of using a value based approach is that it can greatly simplify the design decision making process, a value approach meets the requirements posed by Von-Nuemann and Morgenstern ${ }^{7}$ as value models inherently represent the utility of a design. ${ }^{8,9}$ The challenge, of course, is the actual creation of the value model. There has been a significant amount of work in this area, both commercial and government focused, and the results range from relatively simple to fairly complex.

\footnotetext{
${ }^{*}$ Undergraduate Student, School of Mechanical, Aerospace and Civil Engineering, Sackville Street, Manchester, UK , peter.sutcliffe@student.manchester.ac.uk

${ }^{\dagger}$ Lecturer, School of Mechanical, Aerospace and Civil Engineering, Sackville Street, Manchester, UK, peter.hollingsworth@manchester.ac.uk, AIAA Member
} 


\section{Value and Design Decisions}

Value Driven Design can be formally defined as an improved design process that uses requirements flexibility, formal optimization and a mathematical value model to balance performance, cost, schedule, and other measures important to the stakeholders to produce the best outcome possible. ${ }^{10}$ The traditional requirement driven approach to design has increasingly led to over-inflated budgets and lengthy project overruns. A prime example of this being the Airbus A380 project whose development costs spiraled to $\$ 18$ billion, an overrun of $50 \%$, with a 2 year delay to entry of service. ${ }^{11}$ There are a number of reasons that contribute to the budget and time overruns; inaccurate project estimation, fluctuating currency markets, customisation demands. However, the largest contributing factor is the almost myopic focus on achieving predetermined capabilities often at the expense of simplicity of the system and hence leading to overblown systems. The concept of Value-Driven Design aims to remove this requirement led approach form the design process and hence enable optimisation.

Value Driven Design allows engineers to be freed from the shackles of requirement fulfillment and allows the selection of the best design rather than that which simply meets the preset criteria. Traditional design assumes that all requirements must be met and therefore have the same effect upon the complete system. This is clearly not always the case and as such VDD examines the elements of a project and allows a score or value to be attached to the individual components. A scoring function, known as the objective function, can then be applied to the system to search for the best design and hence the one providing the most value. A value model allows values within a project to be quantified and understood whilst clarifying the relationships that exist between differing objectives. As such it is recognized that certain attributes can have a greater impact upon the value of the design than other. Value models are generally developed by a trained analyst in conjunction with the person whose values are being assessed.

Value Driven Design differs from the conventional approach to systems engineering during the evaluation phase of the process. During the requirement focused design process an assessment is made as to whether the requirements have been met, if not another iteration is carried out. This is a very resource and motivation heavy process which often leads to the aforementioned lengthy delays. At this point in the cycle VDD assigns a score to the design based upon the objective function. If the design has achieved a better score than the previous iteration a decision can be made as to whether another iteration of the process is necessary to achieve a better score or the design can be accepted. ${ }^{12}$ The importance of the scoring system is therefore paramount within Value Driven Design to ensure an objective measure of the value a design can provide.

\section{II.A. Surplus Value}

One straightforward system value model for civil/commercial applications is the Surplus Value method. The surplus value method assumes that the once the costs of the relevant parties have been detracted from the revenue then the surplus value left over is split between the parties as profit, as shown in Eq. 1;13

$$
S V=\text { Profit }_{\text {Total }}=P_{\text {Reservation }}-C_{\text {Manufacturing }}
$$

where the Reservation Price is determined by the value to the customer, that is the maximum that a customer can rationally pay for the product. This is represented in Eq. 2.

$$
P_{\text {Reservation }}=R_{\text {Total }}-C t_{\text {Operating }}
$$

An expansion of Surplus Value can be made to include the cost of development. This is illustrated by Cheung et al., ${ }^{4}$ and given in Eq. 3.

$$
\begin{aligned}
S V & =\text { Disc } \text { Producer } \times \text { Market Size } \\
& \times[\text { Disc } \text { Customer } \times U \\
& \times\left(R_{\text {Flight }}-C_{\text {Flight }}-C_{\text {Delay \& Cancellations }}-C_{\text {Externalities }}\right) \\
& \left.-C_{\text {Manufacturing }}\right] \\
& -C_{\text {Development }}
\end{aligned}
$$

Where the Disc Producer and Disc Customer are the multipliers on future revenue and costs that are dictated by the producer's and customers' discount rates and program investment horizons. These multipliers allow 
for the vision of a program on a single period's basis. The value of the multiplier can be determined using Eq. 4.

$$
\text { Disc }:=\frac{1}{\sigma}-\frac{1}{\left[\sigma \times(1+\sigma)^{t_{\text {Project }}}\right]}
$$

The use of this form provides a relatively straightforward method of determining future value. However, two problems arise. First, there is the issue with determining the investment horizon. Second, there is an issue with communication, discount rates are often quoted as whole percentages. This will generally produce non integer multipliers. However, neither of these are insurmountable. The investment horizon is effectively a function of the discount rate, and it is relatively straightforward to approximate the multipliers as integers to improve communication. Examples of both of these cases are shown in Table 1. The asymptotic effect

Table 1. Discount Multipliers

\begin{tabular}{|c|c|c|c|}
\hline Discount Rate & Investment Horizon & Multiplier & Nearest Integer \\
\hline \hline $10 \%$ & 1 & 0.909 & 1 \\
$10 \%$ & 5 & 3.79 & 4 \\
$10 \%$ & 10 & 6.14 & 6 \\
$10 \%$ & 15 & 7.61 & 8 \\
$10 \%$ & 20 & 8.51 & 9 \\
\hline $15 \%$ & 1 & 0.870 & 1 \\
$15 \%$ & 5 & 3.35 & 3 \\
$15 \%$ & 10 & 5.02 & 5 \\
$15 \%$ & 15 & 5.85 & 6 \\
$15 \%$ & 20 & 6.26 & 6 \\
\hline $20 \%$ & 1 & 0.833 & 1 \\
$20 \%$ & 5 & 2.99 & 3 \\
$20 \%$ & 10 & 4.12 & 4 \\
$20 \%$ & 15 & 4.68 & 5 \\
$20 \%$ & 20 & 4.87 & 5 \\
\hline
\end{tabular}

of discount rates on the multiplier are shown in Figure 1. Looking at both Table 1 and Figure 1, the result is that firms with small discount rates can look at programs with very long total time horizons, while firms with high discount rates will necessarily have much shorter time horizons. In the case of a company with an effective discount rate they can consider looking at investments with life-cycles of 40 years or more. While a capital depleted company with an effective discount rate of $25 \%$ would look no more than 10 years out. They are several implications of this on how programs are structured and sales, lease and maintenance contracts are created. The specific details of which are beyond the scope of this specific paper; however, these implicaitons can be used in both the work contained here-in and future reccomendations.

The use of a surplus value approach, as compared to the standard Net Present Value (NPV) or Expected Net Present Value (ENPV) approaches, requires a few basic and key assumptions to be made. The first and foremost is that future real revenues and costs are assumed to be constant. This seems like a poor assumption on its face; however, when comparing different technology options or design choices what is really being assumed is that the schedule of future real revenues is indifferent to the choices being made. That is if the manufacturing costs, operating costs and revenues are not going to be constant from one year to the next the way these costs will vary will be the same for all of the options being considered. This simplification means that the results produced by the SV approach will differ from those of the NPV approach by a simple constant. ${ }^{4,13}$ The second key assumption is that the investment is viewed in a risk neutral manner. Work by Peoples \& Wilcox ${ }^{2}$ amongst others has investigated the use of ENPV as the design optimization value proposition. 


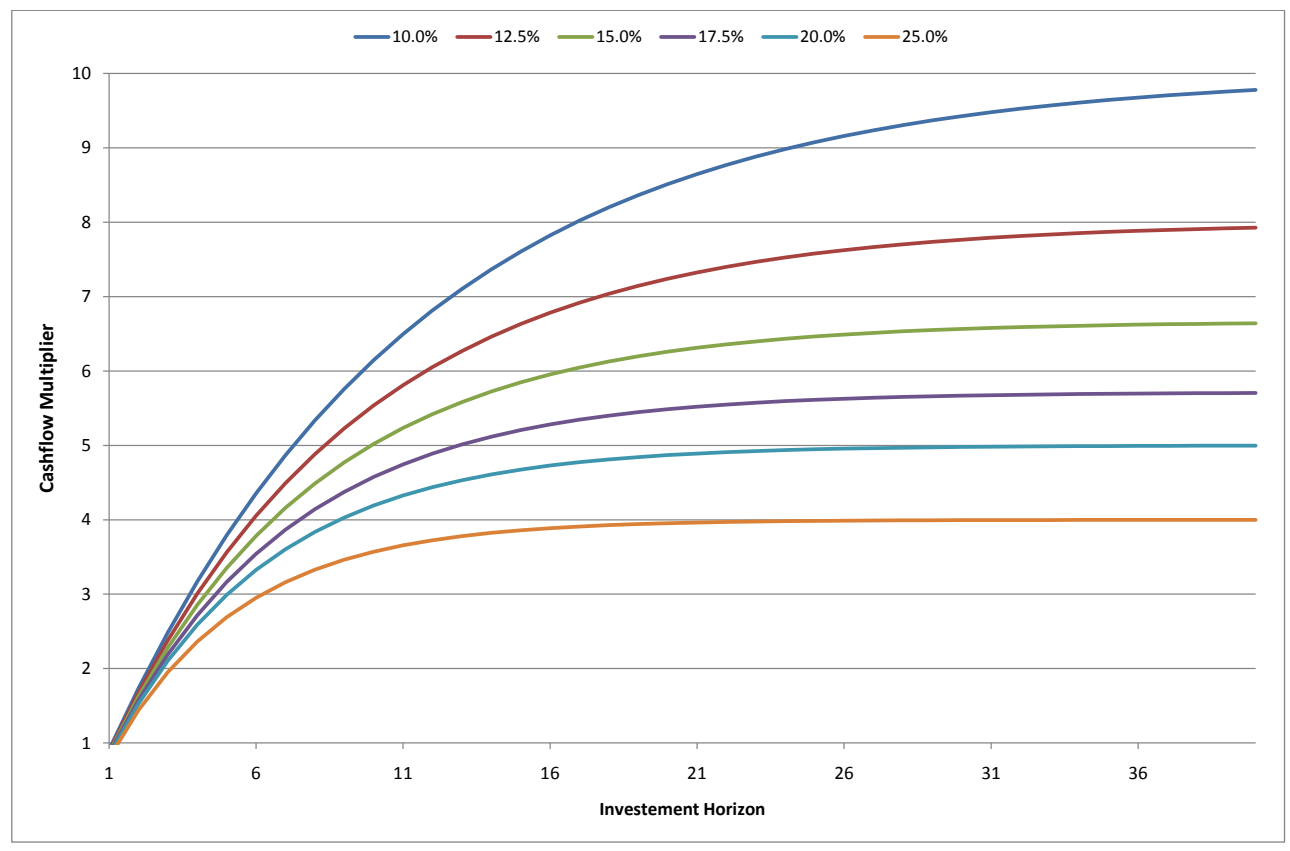

Figure 1. Discount Multiplier as a Function of Rate and Investment Horizon

\section{Revenue \& Pricing}

\section{III.A. Price Elasticity}

An airlines primary consideration when deciding upon the purchase of an aircraft is, quite obviously, the desire to maximize revenue and hence profit. Therefore, before investigating any potential integration of revenue maximization in to the design process, it is important to first investigate how airlines set their prices. When setting prices for aircraft seats, an airlines primary motive is to sell the seats at a sufficiently low price, such as to generate a demand that will sell the capacity whilst simultaneously allowing for maximisation of revenue and hence profit. The primary mechanism for facilitating this generation of value for the airline is the natural elasticity present within the ticket prices. Price elasticity may be formally defined in Eq. $5 ;^{14}$

$$
E=\frac{\partial \ln d}{\partial \ln p}=\frac{\% \Delta d}{\% \Delta p}=\frac{\Delta d / d}{\Delta p / p}
$$

In real terms, this can be translated as the freedom that exists within the pricing of tickets and how it impacts upon the ability to generate profit. The figure generated for price elasticity should intuitively be less than zero, reflecting the naturally expected drop in demand in response to a rise in fare, the reverse also being true. However, a figure between zero and minus one reflects an inelastic market, meaning that a rise in fare will have a proportionally smaller effect on the demand for seating. This is obviously a favorable situation and one that lends itself to the generation of revenue.

\section{III.B. Market Factors Influencing Price Elasticity}

The calculation of price elasticity is a very difficult task and is often situation and route dependent. A separation can also be made between the short term and long term price elasticity, as in the long term consumers display a greater ability to adjust to the fare levels. ${ }^{15}$ This finding is borne out by Fridstrom \& Thune-Larsen ${ }^{16}$ in their study of the Norwegian market, showing that the elasticity present drifted from -0.69 in the short term to -1.63 in the long term. This study carries the caveat of being performed in a 
small domestic market with relatively few substitution choices available to the consumer due to the nature of Norway's terrain. This makes the analysis of the multitude of studies that have been carried to estimate price elasticity and the factors that influence it a very complex issue. Thus, establishing the validity of the results presented is an important obstacle to be crossed before any incorporation can be made in to the design process. One of the most important differences that can be made in the demographic of passengers is that between the leisure and business travelers. Passengers traveling for business purposes have a tendency to be more inelastic and hence less sensitive to changes in air fares. The potential inelasticity that exists within the business market is one that has been frequently studied and attempts to calculate it are numerous. The various studies are often route specific and offer an insight in to the various reasons for the assumed inelasticity. Brons et al, ${ }^{17}$ postulate two reasons for this relative inelasticity;

- The value that a business class traveler will associate to the time factor of travel. As business class airfares are generally much more expensive than their economy class counterparts any rise in price for the two will be proportionally lower for the business class traveler. This implies that any rise in price will have a similarly proportional lower impact upon the amount of the travel budget associated with this section of the journey.

- The value of service that business class travelers expect whilst flying and hence the ability to make the most of their time spent traveling.

These two factors can be distilled, together with variable such as flight frequency and aircraft size, as the overall quality of service offered by a carrier. Previous to airline deregulation in 1978 it was assumed that demand was inelastic to quality of service issues, generally due to a lack of substitution. However, since the liberalization of the skies and the inherent route competition that this has brought quality of service has now become a large differentiating factor for consumers. The ability to fly to destinations non-stop appears to be overriding concern for passengers in the study carried out by Ghobrial \& Kanafani ${ }^{18}$ in quality of service model for services between US cities, with a $10 \%$ increase in flight frequency bringing only a $4.4 \%$ in passenger demand. However, one of the models used produced during the report suggests that traffic on routes with an intermediate stop, such as that practised by "hub and spoke", will carry $66.3 \%$ less traffic than the direct route when the model was ran under the assumption that the passengers spent an hour in transit at an intermediate airport. This emphasises the importance that passengers appear to place upon the directness of their route. Clearly the comparative cost of these routes will have an effect on whether a customer chooses to travel directly or not. Oum, Zhang, \& Zhang ${ }^{15}$ suggest in their work that their is evidence that firms have a tendency to price more competitively on longer distance routes than on short haul routes. This would obviously have an effect upon the directness of route a customer chooses. The study also found that the timing of flights appears to be crucial consideration with passengers applying a $50 \%$ greater weighting to peak travel as opposed to off-peak. This would appear to indicate that a greater elasticity will exist within the market that that travels at peak hours due to the relative inflexibility of their schedules. A similar European wide study carried out by Jorge-Calderon ${ }^{19}$ found that short haul markets show a greater sensitivity to the frequency of flight with the situation being reversed in the long haul market, implying the presence of a positive correlation between flight frequency and elasticity present within a market.

A problem with these studies is that they assume all travelers have the same end goal in so much as that they do not differentiate between the reasons for a consumer's journey. Proussaloglou \& Koppelman ${ }^{20}$ carried a comprehensive study in to the influencing factors behind a passenger's choice of carrier. By mailing out surveys in the major hub cities of Dallas and Chicago, American and United respectively, and analyzing the responses allowed travelers to be sorted in to leisure and business categories. From a sample size of 2006, it was found that $20 \%$ of the respondents accounted for more than half the total trips taken. With the majority of these trips being taken for business purposes it is clear that this type of traveller is vital to carrier revenues. The model used allowed a prediction to be generated of the impact changes in service variables such as fare, convenience and on-time reliability would have upon the distinct groups of travellers. A rating scheme was determined based upon four different customer surveys which asked the customers to rate services such as on-time reliability, the schedule flexibility offered by the carrier's flights, safety performance, low fares, and overall service quality on a five point scale. It showed that on-time reliability has the greatest effect in the probability of a carrier being chosen in both the frequent and infrequent flyer categories, with a half percent increase in rating given to the carrier in reliability bringing a $6 \%$ and a $4 \%$ increase in ridership respectively. This is also borne out by Holloway ${ }^{21}$ who found that a $1 \%$ improvement in on-time performance led to a $0.43 \%$ increase in passenger demand. It can be reasoned that this occurs due to the removal of uncertainty 
in the passengers mind and thus improves brings an added value. The model also indicated that a half point increase in low fare rating brought about a $5 \%$ increase in non-business travel but only $2 \%$ increase in the business market. The approach employed assumed that the market share was initially split evenly between two carriers and as such the figures generated must be taken with a pinch of salt, although it does indicate the importance that all types of customer place upon reliability.

The model used allowed a prediction to be generated of the impact changes in service variables, such as fare, convenience and on-time reliability, would have upon the distinct groups of travellers. A rating scheme was determined based upon four different customer surveys which asked the customers to rate services such as on-time reliability, the schedule flexibility offered by the carrier's flights, safety performance, low fares, and overall service quality on a five point scale. The model showed that on-time reliability has the greatest effect in the probability of a carrier being chosen in both the frequent and infrequent flyer categories, with a half percent increase in rating given to the carrier in reliability bringing a $6 \%$ and a $4 \%$ increase in ridership respectively. This is also borne out by Holloway ${ }^{21}$ who found that a $1 \%$ improvement in on-time performance led to a $0.43 \%$ increase in passenger demand. It can be reasoned that this occurs due to the removal of uncertainty in the passengers mind and thus brings an improvement in added value. The model also indicated that a half point increase in low fare rating used brought about a $5 \%$ increase in non-business travel but only $2 \%$ increase in the business market. This indicates that a rise in prices will have less impact upon business passengers than leisure passengers backing up the airlines assumption of inelasticity in that demographic. Provided that such factors as on-time performance and frequency of flight can be addressed this allows for the possibility of price rises in the business sector whom comprise the largest portion of the passengers being flown. The approach employed assumed that the market share was initially split evenly between two carriers and as such the figures generated must be taken with a pinch of salt, although it does indicate the importance that all types of customer place upon reliability.

Examination of the findings of the various surveys reveals that there are numerous factors that influence a passengers decision to travel upon a certain airline, these are summarized in Figure 2; It is clear that

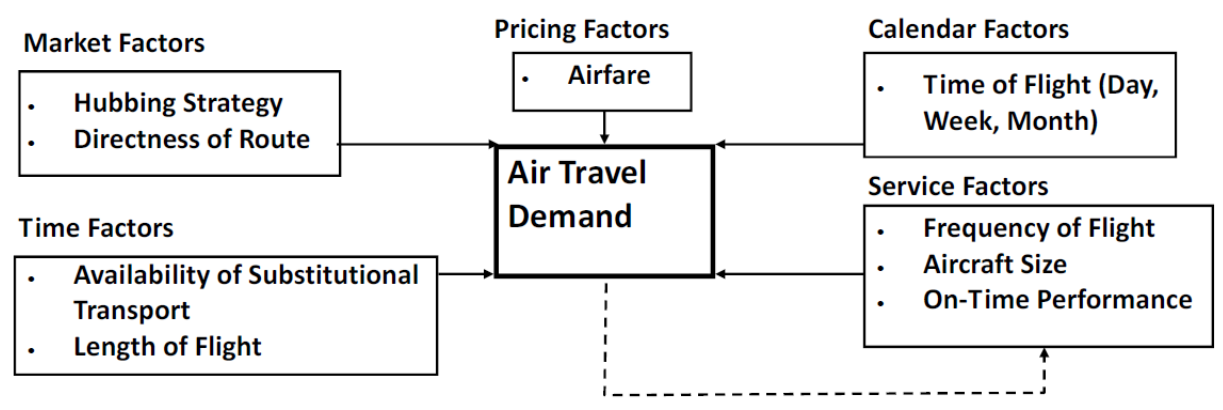

Figure 2. Air-Travel Demand Factors

some of these factors take precedence over others in the minds of the customers and the decisions that they make when selecting their travel arrangements. The data examined points to the fact that price elasticity, and hence an airlines ability to raise prices, is very passenger type and route specific, therefore it would be incorrect to make any sweeping generalizations about the prevailing aircraft market. However, it appears that on-time performance is the most consistent factor across a spread of markets and passenger demographics. Although the frequency of flight was shown to become less important as the length of the journey increased it can still be considered an important factor, especially within the US domestic market, due to the relatively short distances being flown within the market. With these over-riding issues in mind, it would seem prudent to examine the root causes behind the degradation of on-time performance and frequency of flight.

\section{Example Case}

For most aircraft development programs that choices made will have relatively small effects on the potential passenger yield. However, when concept level design choices are being made the potential for altering the yield curve exists. One example of an aircraft concept that could, potentially, alter the yield curve is the Cruise Efficient Short Take-Off and Landing (CESTOL) concept. The idea behind the CESTOL is to produce an aircraft with STOL or near STOL capabilities that does not suffer from the same cruise performance as a conventional take-off and landing (CTOL) aircraft of equivalent payload and range. ${ }^{22}$ The 
idea is that a CESTOL vehicle will enable the use of currently under/unused runways at existing large airports and the offloading of some traffic from highly congested major airport to existing general aviation airports in the same region. The issue with the CESTOL concept is that even with advanced technology CESTOL aircraft alway suffer from a weight and cost penalty compared to existing and future CTOL designs. This coupled with the fact that many regional airports current lack either the airside or landside facilities to support commercial operations makes it hard for both aircraft manufacturers and airlines to justify the introduction of the CESTOL. One option is to look into the possibility of using aircraft with CESTOL or nearer to CESTOL performance to relieve highly congested airports with currently underused runways.

Instead of designing a CESTOL aircraft that is capable of flying $3000 \mathrm{~nm}$ carrying 170 passengers and baggage and expecting it to operate in and out of reliever airports with runway lengths of less than 4,500 ft some have suggested that a more realistic goal is to look at an aircraft that can operate out of shorter fields for the majority of its missions, but would use more runway length if required to operate to the full extent of its design range. The evidence from the elasticity studies suggest that for shorter range missions the yield will be more sensitive to changes in scheduled block time and expected delays. ${ }^{19}$ This would provide a perfect example of where an analysis that investigates the potential for yield variation might provide a benefit to the customer. Hahn ${ }^{23}$ performed a sizing study on a 108 passenger CESTOL regional jet. In his comparison, which he made to a notional aircraft similar in size and performance to the Embraer E190, that for every reduction in 1 foot of take-off field length for a $500 \mathrm{~nm}$ mission there was a penalty of about $1.2 \mathrm{lb}$ of fuelburn on the $2400 \mathrm{~nm}$ mission and about $0.5 \mathrm{lb}$ on a $500 \mathrm{~nm}$ mission, carrying 100 passengers. This equates to about 37 gallons of extra fuel for a $500 \mathrm{~nm}$ mission and about 96 gallons of extra fuel for the $2400 \mathrm{~nm}$ mission for each $500 \mathrm{ft}$ of field length reduced. This was achieved by increasing the wing area, without any more exotic technologies to increase the maximum lift coefficient or descent angles.

The issue with the increased fuelburn and increased aircraft weight is that it drives up all of the aircraft related costs. This means that, from a cost basis it is very hard to justify a STOL aircraft, even if you do not take any cruise speed penalties. In fact while NASA and others have been promoting the concept of STOL aircraft for more than twenty years no airline has invested in a STOL aircraft when a non-STOL alternative is available. If, however, the concept of cruise efficient STOL is revisited in the face of varying yield possibility, it might be possible to devise an aircraft that is justifiable from a business case, operating from existing commercially served airports.

\section{IV.A. Airports with Constrained Operations Limits}

One of the problems with increasing demand for air travel, and particularly for air travel over relatively short distances, is that there are some serious airport capacity constraints. This is particularly true in the North East United States. Furthermore, many of these airports have either underused crossing runways or runways designed for regional turboprop aircraft. There many other airports where crossing runways exist. In many cases these runways are either little used or if they are used lead to significant reductions in low visibility operations rates. Three examples of airports with these configurations are shown in Figure 3 . In the case of Figures 3(a) and 3(b), the crosswind configuration is part of the high volume operational plan for the airport, either for departures or using a technique known as Land Hold Short (LAHSO). In the case of the third airport, Detroit, shown in Figure 3(c), the crosswind runway is not typically used during high volume operations.

The problem with LAHSO operations is that they can only be performed when the pilots are able to visually ensure separation from other aircraft, i.e. only during good weather. This means that as soon as the visibility drops the LAHSO operations are curtailed and the operations rate for the airport drops. For instance in the case of Newark International Airport, Figure 3(a), a reduction in visibility from optimal to full Instrument Flight Rules (IFR) conditions sees the the operations rate drop from between 84 and 92 operations and hour to only $61-66$ operations per hour, ${ }^{27}$ a drop of almost $34 \%$. Correspondingly Detroit International Airport sees a corresponding reduction in capacity of only $28 \%$, and Atlanta Hartsfield of $16 \% .{ }^{27}$ The consequence of the reduction in capacity is that fewer flights can be scheduled and ultimately increased delays. Looking at Figure 4 indicates that both Newark and New York LaGuardia were scheduled near optimum capacity for most of the summer of $2004 .^{27}$ 


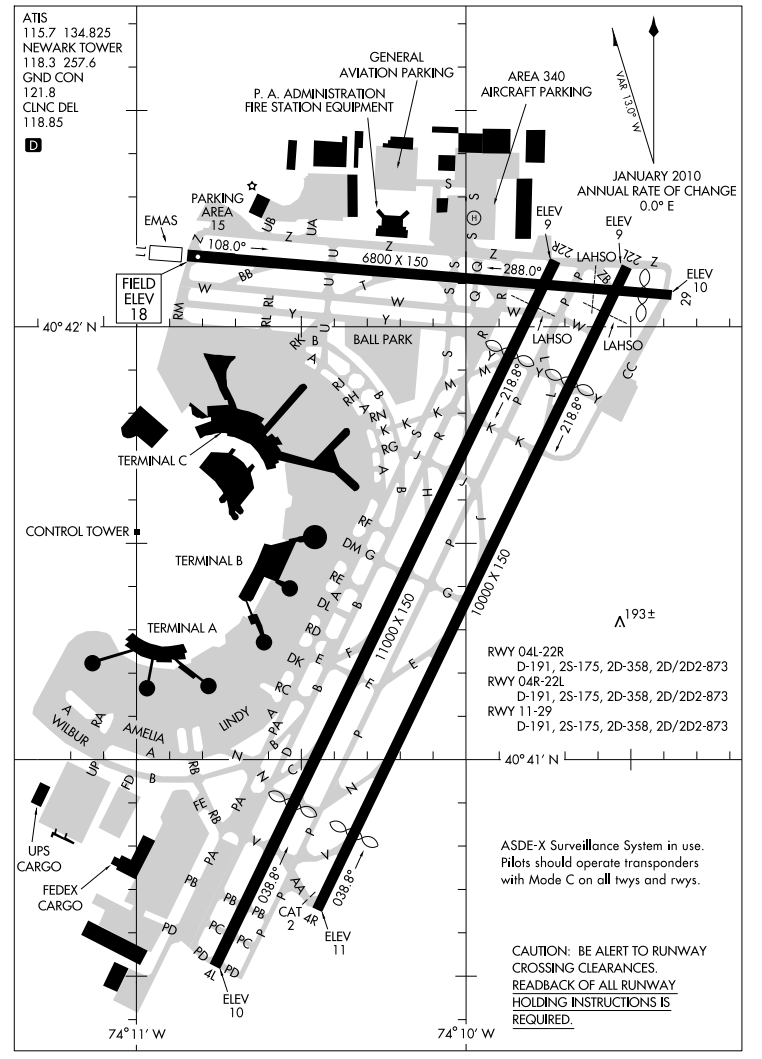

(a) Newark International Airport ${ }^{24}$

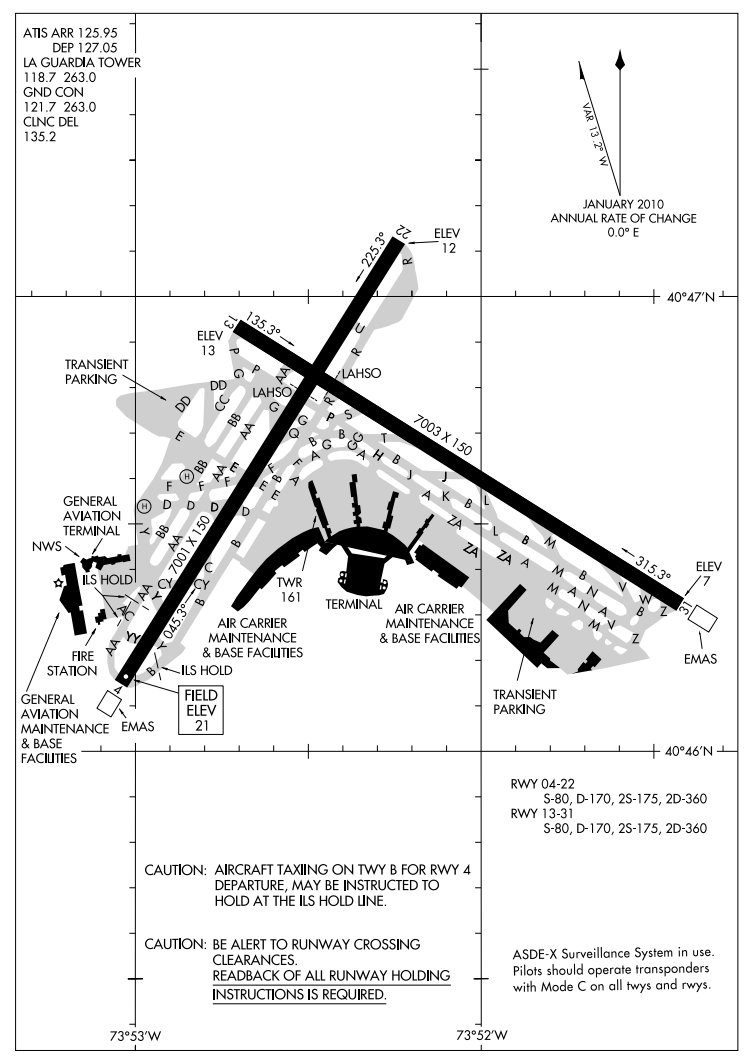

(b) New York Laguardia Airport ${ }^{25}$

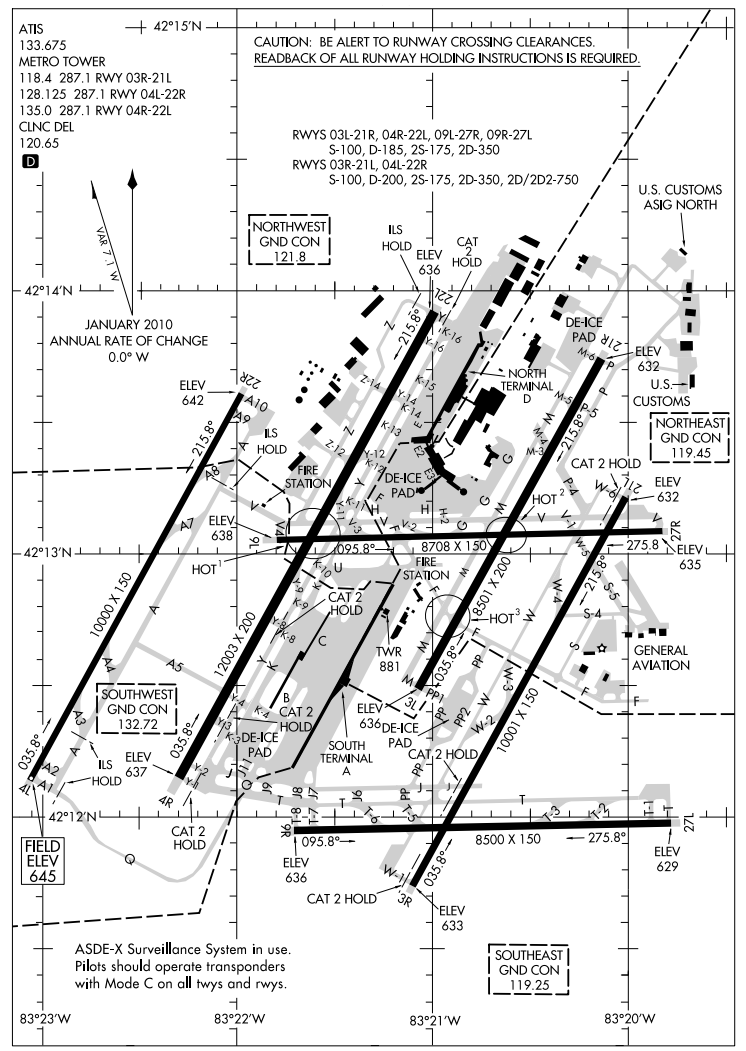

(c) Detroit Metropolitan Airport ${ }^{26}$

Figure 3. Example Airport Diagrams with Crossing Runways 


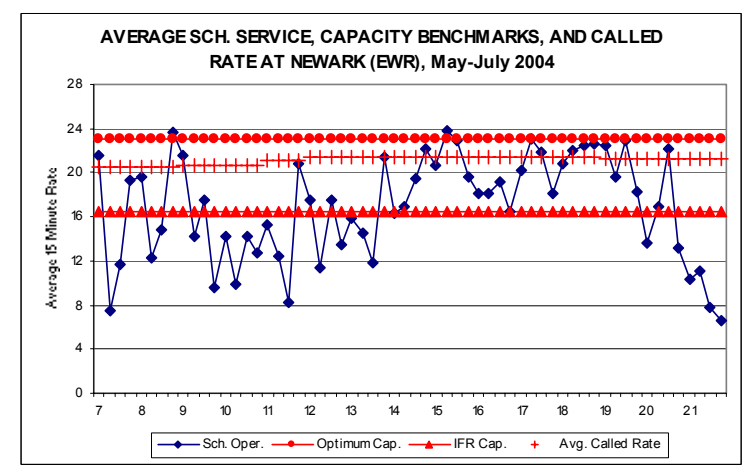

(a) Newark International Airport ${ }^{27}$

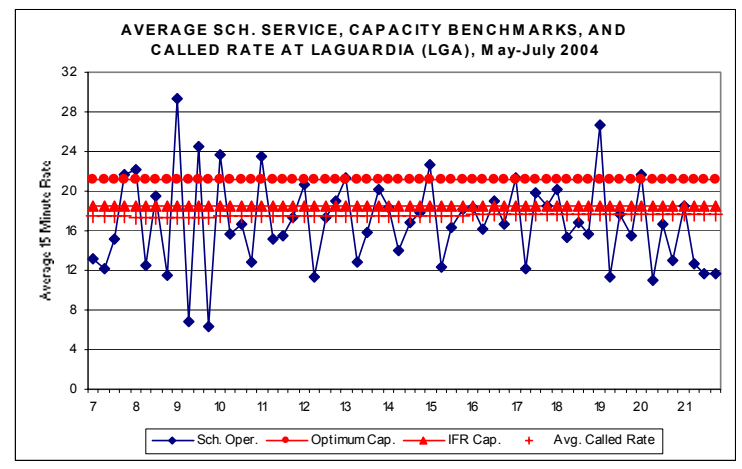

(b) New York Laguardia Airport ${ }^{27}$

Figure 4. Summer 2004 Airpot Schedule vs. Operational Capacity Benchmark

\section{IV.B. Revenue Requirements for STOL RJ}

Returning to Hahn's STOL RJ concept ${ }^{23}$ which operates out of shorter fields on shorter stage lengths. Using Hahn's fuelburn numbers, increases in gross weight, it is straightforward to determine a portion of the increase in operating cost, those portions associated with fuelburn and service fees. What is harder to determine from Hahn's results are the increases in maintenance costs associated with both the larger airframe and the increased engine thrust and the increase in manufacturing cost. However, even without this information it is relatively easy to demonstrate the usefulness of the surplus value approach in comparing two aircraft concepts and the ability of use variation in yield potential to determine if the aircraft concept is viable.

Returning to Section II.A and Eq. (3) it is possible to determine what improvement in revenue is necessary to offset an increase in costs. To determine the delta in cost for this example the following cost structure was used:

- Fuel Cost per gallon: ${ }^{28} \$ 2.15$

- UK NATS enroute charge: ${ }^{29} \$ 75$ per chargeable service unit

- Manchester international airport Take-off fee: ${ }^{30} \$ 9.80$ per tonne MTOW

- Manchester international airport terminal air traffic service charge: ${ }^{30} \$ 3.63$ per tonne MTOW

The changeable service unit is a combination of aircraft MTOW and distance flown. This is represented in Eq. (6)

$$
C S U=\frac{M T O W_{\text {tonne }}}{50} \cdot \frac{\text { distance }_{k m}}{100}
$$

where the distance is the en-route great circle distance between two airports minus $40 \mathrm{~km}$ at each end. As an example the en-route distance for a $500 \mathrm{~nm}$ flight would be $846 \mathrm{~km}$.

The resulting increase in fuel costs and fees, from the notional CTOL aircraft are shown in Table 2.

Table 2. Comparison in Cost for STOL vs. CTOL RJ, 500 nautical mile mission

\begin{tabular}{|l|c|c|c|c|c|c|}
\hline Field Length & Fuel Cost & Fuel \% Diff & Airport Fees & Airport \% Diff & En-route Fees & En-route \% Diff \\
\hline \hline $4000 \mathrm{ft}$ & $\$ 95$ & 3.0 & $\$ 6.90$ & 1.0 & $\$ 3$ & 0.5 \\
$3500 \mathrm{ft}$ & $\$ 174$ & 5.7 & $\$ 15.90$ & 2.4 & $\$ 8$ & 1.2 \\
$3000 \mathrm{ft}$ & $\$ 251$ & 8.1 & $\$ 38.39$ & 5.7 & $\$ 19$ & 2.8 \\
\hline
\end{tabular}

The corresponding fuel cost and fee increases for the 2400 nautical mile mission is shown in Table 3. Note that the percent differences for the fees are identical as they are based solely on MTOW.

If it assumed that load factor is completely independent of the fare charged, a poor assumption but one that serves to illustrated the concept, then to achieve the same surplus value the revenue potential of the 
Table 3. Comparison in Cost for STOL vs. CTOL RJ, 2400 nautical mile mission

\begin{tabular}{|l|c|c|c|}
\hline Field Length & Fuel Cost & Fuel \% Diff & En-route Fees \\
\hline \hline $4000 \mathrm{ft}$ & $\$ 246$ & 2.8 & $\$ 17$ \\
$3500 \mathrm{ft}$ & $\$ 453$ & 5.3 & $\$ 39$ \\
$3000 \mathrm{ft}$ & $\$ 652$ & 7.6 & $\$ 93$ \\
\hline
\end{tabular}

aircraft would have to increase with the operating costs. Returning to Eq. (3) and rearranging to solve for required revenue based upon an assumed surplus values gives Eq. (7).

$$
\begin{aligned}
R_{\text {Flight }} & =C_{\text {Flight }}+C_{\text {Delay \& Cancellations }}+C_{\text {Externalities }} \\
& +\frac{1}{(\text { DiscC } \times \text { Utilization })}\left[C_{\text {Manufacturing }}+\frac{\left(\text { SV }+C_{\text {Development }}\right)}{(\text { Disc } P \text { Market Size })}\right]
\end{aligned}
$$

where $R_{\text {Flight }}$ can be approximated by

$$
R_{\text {Flight }}=\text { Seats }_{\text {Avail }} \times L F_{\text {Pax }} \times P_{\text {Pax }}+\text { Cargo }_{\text {Cap }} \times L F_{\text {Cargo }} \times P_{\text {Cargo }}
$$

For the sake of this example we will assume that all of the externality costs are included in the fuel prices and navigation and airport service fees. This combines $C_{\text {Flight }}$ and $C_{\text {Externalities }}$ into a single value. Additionally, we will assume that the market size, utilization, discount multipliers and development costs are constant between the conventional and CESTOL concepts. Again, these last assumptions are not strictly speaking true, but in the first order are can be reasonable. The development and certification cost is driven more by technology development and certification than the the incremental increase in aircraft size. In the case of the aircraft presented by Hahn, there is very little if any technology difference between the different concepts so the costs should be relatively similar.

If all we are doing is comparing the surplus value or required revenue between the two concepts, i.e. $S V_{2}-S V_{1}$ or $R_{2}-R_{1}$ then the constant values can be ignored. This means that Eq. (7) can be approximated as Eq. (9).

$$
\begin{aligned}
R_{\text {Flight }} & =C_{\text {Flight }}+C_{\text {Delay \& Cancellations }} \\
& +\frac{1}{(\text { Disc } \times \text { Utilization })}\left[C_{\text {Manufacturing }}+\frac{S V}{(\text { Disc } P \text { Market Size })}\right]
\end{aligned}
$$

Solving for the differnce between two airccraft concepts assuming that the surplus values are the same, $S V_{2}=S V_{1}$, gives Eq. (10).

$$
\Delta R_{\text {Flight }}=\Delta C_{\text {Flight }}+\Delta C_{\text {Delay } \& \text { Cancellations }}+\frac{\Delta C_{\text {Manufacturing }}}{\text { Disc } C \text { Utilization }}
$$

Rearranging to put the delay and cancellations cost with revenues allows a pretty simple representation of the required changing in revenue related to cost.

$$
\Delta\left(R_{\text {Flight }}-C_{\text {Delay \& Cancellations }}\right)=\Delta C_{\text {Flight }}+\frac{\Delta C_{\text {Manufacturing }}}{\text { Disc } C \text { Utilization }}
$$

There are several ways to look at this. From viewing revenue as independent of delays and that the delays and cancellations are direct costs in compensation to assuming that there are no direct costs associated with delays and cancellations and that all of the impact will be in reduced revenue potential. In truth there is a mixture. As Holloway ${ }^{21}$ and Proussaloglou \& Koppelman ${ }^{20}$ indicate there is a revenue impact, i.e. demand, with respect to on-time performance. There are also some direct costs associated with delays and cancellations. These include crew costs, ground handling charges, and fuel costs in addition to passenger compensation and rescheduling requirements.

The worst case economic scenario for a potential CESTOL aircraft is where the airline suffers no direct cost from delays and only sees a benefit in demand. In this case CESTOL operations would reduce the number of delayed flights, both broadly, and more specifically for CESTOL. Couluris et al. indicated that the introduction of a ESTOL, similar to a CESTOL aircraft but with better field performance, could potentially reduce the 2016 delay profile at Newark International Airport by $75 \% .{ }^{31}$ Taking that the current delays at Newark effect approximately $16.5 \%$ of all arriving flights, there is a substantial scope for improvement in 
on-time performance. Looking deeper into Couluris' figures the reduction in arrival delays is about $85 \%$, while departure delays decrease by only $24 \% .{ }^{31}$ This is because the redesign of the Newark operations uses runway 11, see Figure 4(a), for ESTOL arrivals, with departures sequenced with regular flights. Since the CESTOL proposed by Hahn ${ }^{23}$ could easily land on runway 11, and any departures less than $500 \mathrm{~nm}$ could also used runway 11, for reverse operations. It is reasonable to assume that the arrival benefits would be comensurate.

Using the assumption that CESTOL operations would see a $85 \%$ reduction in arrival delay and constitute about $35 \%$ of operations. In July $200929.4 \%^{32}$ of flights at Newark airport were considered to have arrived late, with the reduction in airspace and runway delays implied by Couluris this would have been abot $21 \%$. In June 2010 the corresponding numbers would have been $24.7 \%{ }^{32}$ and $16.1 \%$ respectively. The reduction is smaller in the winter; however, assuming that it would average increase the percentage of on-time arrivals by $8.5 \%$, the overall on-time performance would trend from $71.6 \%^{32}$ to $80.1 \%$.

This can be translated into revenue potential by using demand elasticity. Using Holloway's factor, $0.43,{ }^{21}$ or Proussaloglou \& Koppelman's, 0.30 to $0.46,{ }^{20}$ in Eq. (12) produces demand change as represented in Table 4.

$$
d_{2}=d_{1} \times E\left(\frac{O T P_{2}}{O T P_{1}}-1\right)
$$

Table 4. Demand Increases Resulting from On-Time Performance Improvement at Newark

\begin{tabular}{|l|c|c|}
\hline Source & Elasticity Factor & Demand Multiplier \\
\hline \hline Holloway & 0.43 & 1.057 \\
Proussaloglou \& Koppel- & 0.30 & 1.036 \\
man (Average) & & 1.055 \\
$\begin{array}{l}\text { Proussaloglou \& Koppel- } \\
\text { man (Business) }\end{array}$ & 0.46 & \\
\hline
\end{tabular}

This gives the potential increase in demand and hence revenue potential from the broad introduction of CESTOL operations at Newark. However, no single airline will make the required investment for a new aircraft concept when the entire benefit is spread evenly. The simple action is to apply the on-time performance benefit to CESTOL flights only and calculate them in the revenue column in the SV calculations.

Another option is to apply a decrement to the delay and cancellation cost factor for those CESTOL flights that are less than $500 \mathrm{~nm}$ in length. Looking at the mix of flights arriving into and departing from Newark Airport that are 110 seats or fewer approximately $44 \%$ of them are on missions of less than 500 nautical miles. ${ }^{33}$ Assuming a cost of $\$ 35$ per hour of delay. The improvement described by Couluris would result in a typical reduction in delay of about 8 minutes. ${ }^{34}$ This translates into a savings of about $\$ 6.67$ per passenger on these flights. Using a load factor of $85 \%$, this would mean that each 110 seat, 500 nautical mile flight would see a delay reduction of $\$ 439$.

If this reduction in loss is directly realizable, i.e. it is currently a cash cost to the airline, then returning to Eq. (10) we can calculate the difference in required revenue and accompanying yield. In this case we will use Holloway's ${ }^{21}$ on-time performance elasticity and assume the manufacturing and maintenance costs for the two aircraft are the same. This simplifies Eq. (10) to the following.

$$
\Delta R_{\text {Flight }}=\frac{\Delta C_{\text {Flight }}+\Delta C_{\text {Delay \& Cancellations }}}{1.057}
$$

Revisiting Tables 2 and 3, the resulting change in required improvement in revenue is shown in Table 5 If the delay cost improvements are not realizable then the Revenue requirements are given in Table 6 .

Table 5. Revenue Change Required for CESTOL Aircraft to Have Equal Surplus Value, Full Delay Cost is Realizable, No Impact on Load Factor

\begin{tabular}{|c|c|c|}
\hline $500 \mathrm{~nm}$ Field Length & $\Delta$ Cost & $\Delta$ Revenue \\
\hline \hline $4000 \mathrm{ft}$ & $\$ 197$ & $-\$ 229$ \\
$3500 \mathrm{ft}$ & $\$ 372$ & $-\$ 64$ \\
$3000 \mathrm{ft}$ & $\$ 574$ & $\$ 128$ \\
\hline
\end{tabular}


Table 6. Revenue Change Required for CESTOL Aircraft to Have Equal Surplus Value, Delay Cost is not Realizable, No Impact on Load Factor

\begin{tabular}{|c|c|c|}
\hline $500 \mathrm{~nm}$ Field Length & $\Delta$ Cost & $\Delta$ Revenue \\
\hline \hline $4000 \mathrm{ft}$ & $\$ 197$ & $\$ 186$ \\
$3500 \mathrm{ft}$ & $\$ 372$ & $\$ 355$ \\
$3000 \mathrm{ft}$ & $\$ 574$ & $\$ 543$ \\
\hline
\end{tabular}

In the first case the CESTOL would show good for all but the shortest field length. In the second case, there would need to be an increase in fare that accompanies the introduction of CESTOL aircraft. This brings up the fare elasticity. Using Fridstrom \& Thune-Larsen's long-term elasticity factor of $-1.69,{ }^{16}$ or Adrangi \& Raffiee's updated elasticity of $-1.98,{ }^{35}$ and Eq. (14) allows a quick estimation of the required change in yield. This is shown in Table 7

$$
1+\frac{\Delta R_{\text {Flight }}}{R_{\text {Flight }}}=\frac{\left[E \times\left(\frac{p_{2}}{p_{1}}-1\right)+1\right]}{L F_{1}}\left(\frac{p_{2}}{p_{1}}\right)
$$

The outcome of this is that if there an alternative has an increase in fixed cost per operation, but no or

Table 7. Yield Change Required to Justify CESTOL Design (Surplus Value Equivalence),Delay Cost is not Realizable, Load Factor Adjusts with Fare

\begin{tabular}{|c|c|l|l|}
\hline $500 \mathrm{~nm}$ Field Length & $\Delta$ Revenue & $\begin{array}{l}\frac{\text { Fare }_{2}}{\text { Fare }_{1}} \text { for \$190 Fare, } \\
-1.69 \text { Elasticity }\end{array}$ & $\begin{array}{l}\frac{\text { Fare }_{2}}{\text { Fare }_{1}} \text { for } \$ 190 \text { Fare, } \\
-1.98 \text { Elasticity }\end{array}$ \\
\hline \hline $4000 \mathrm{ft}$ & $\$ 186$ & 0.983 & 0.988 \\
$3500 \mathrm{ft}$ & $\$ 355$ & N/A & 0.978 \\
$3000 \mathrm{ft}$ & $\$ 543$ & N/A & N/A \\
\hline
\end{tabular}

low marginal cost to carry extra payload the long-term elasticities indicate that it is useful to lower cost to increase value and minimize loss. Of course, this is very much dependent upon the assumptions made. Further, the original aircraft would also generate more revenue if fares were lowered as the demand elasticity would drive up traffic faster than the drop in fare would lower per passenger revenue. This is a well known issue with simple linear elasticities.

\section{IV.C. Observations on Example Case}

The CESTOL/STOLRJ example given above is, admittedly, a crude one. It uses one airport as the basis for determining the potential benefit of the STOLRJ aircraft and applies that benefit to the system as a whole, both locally to the airport and more broadly to the overall aviation system. The side-effect of this is that while it is possible to equate the Surplus Value between the STOLRJ and conventional alternatives, by changing the revenue potential, simplistic models may produce confusing results, such as lowering the fare charged for an aircraft that costs more to operate. This is an outcome of the use of simple linear elasticity models with negative slopes that are greater than one. In fact the steeper the slope the easier it is to make more money by cutting fares. This is actually the premise of the charter airlines, which generally have the maximum number of seats which they sell at a relatively low cost to maximize their profit, and as such there is almost no way to justify the use of higher fares to offset the higher costs of an STOL aircraft. Of course linear elasticities are only useful around the datum point.

While the example case is shown to be trivial, i.e. the assumptions made indicate that it is never feasible to design the STOLRJ vehicle as no single airline will purchase an aircraft that costs more to operate if it provides a universal benefit to those operators that choose not to operate the vehicle. For example in this exercise the delay benefit from ESTOL was applicable to all operations at Newark International as long as requisite number of ESTOL operations were met, ${ }^{31}$ it does illustrate that bringing revenue into the equation can be potentially useful. The failure of the example to demonstrate a case where the CESTOL/STOLRJ is a worthwhile design option is because the demand elasticities are effectively the same for the two aircraft. Unfortunately, while there is evidence to suggest that increasing flight frequency has a beneficial effect on demand, the implementation requires a more sophisticated model that includes aircraft size and scheduling, 
i.e. beyond the scope of this paper but well within the broader value-driven approach. A good starting point for just such and implementation would be the work by Cheung et al. ${ }^{4}$

\section{Implications of Using Variable Revenue Potential}

As a result the basic framework needs to be revisited. Returning to Eqs. (7) through (11), it is possible to develop a simple method for understanding the relationship between changes in cost of different concepts and different capability. By using more sophisticated elasticity and cost relationships it possible to compare the diverse systems. In fact the the introduction of an aircraft like the CESTOL would, at least in the short and medium term, allow more flights to be operated out of Newark airport with the same level of delay, the airline could operate more short range CESTOL/STOLRJ flights into and out of Newark, increasing the service load for stage lengths less than $500 \mathrm{~nm}$. While the indication is that demand is relatively inelastic to service frequency, the evidence suggests that the elasticity is higher for short flights. Also, there are cases where when multiple airlines are competing one a route, especially those where some of the airlines offer direct service while others offer only indirect service the cross-price elasticity is greater than negative one. ${ }^{36}$ This would indicate that it is possible to raise prices. The combination of these two factors would allow a single airline operating an aircraft that provides greater capability to schedule flights to achieve a net growth in base demand that can be offset by raising fares.

\section{V.A. Comments on the Use of Revenue}

Consequently, it is possible, and often advisable to investigate implement the use of revenue variation capabilities when investigating the design of sufficiently different aircraft concepts, e.g. the conceptual and early preliminary design stages. This is enabled by using an NPV or SV based approach for the overall system. By doing this the farce that is assumed profit margin or estimated selling price is avoided and making it easier to compare two designs on a "like-for-like" basis. However, it is essential that an understanding of the top-level demand elasticities, i.e. price, schedule, delay, etc. are included. Furthermore, no matter what technologists might say there may not be sufficient incentives in the current structure to show that a concept is good on its own merits. For instance, if a CESTOL aircraft increases on-time performance for all aircraft equally, there will be no justification for the expense of operating a CESTOL aircraft in place of a conventional aircraft. It requires that the incentive and revenue potential effect the alternative concept differently from the conventional/baseline concept.

\section{References}

${ }^{1}$ Markish, J. and Wilcox, K., "Value-Based Multidisciplinary Techniques for Commercial Aircraft System Design," AIAA Journal, Vol. 41, 2003, pp. 2004-2012.

${ }^{2}$ Peoples, R. and Wilcox, K., "Value-Based Multidisciplinary Optimization for Commercial Aircraft Design and Business Risk Assessment," Journal of Aircraft, Vol. 43, No. 4, July-August 2006, pp. 913-921.

${ }^{3}$ Wilcox, K. and Wakayama, S., "Simultaneous Optimization of a Multiple-Aircraft Family," Journal of Aircra, Vol. 40, No. 4, July-August 2003, pp. 616-622.

${ }^{4}$ Cheung, J., Scanlan, J., Wong, J., Forrester, J., Eres, H., Collopy, P., Hollingsworth, P., Wiseall, S., and Briceno, S., "Application of Value-Driven Design to Commercial Aero-Engine Systems," 10th AIAA Aviation Technology, Integration, and Operations (ATIO) Conference, American Institute of Aeronautics and Astronautics, Fort Worth, TX, 13-15 September 2010.

${ }^{5}$ Brown, O. and Eremenko, P., "Application of Value-Centric Design to Spacecraft Architectures: The Case for the Fractionated Spacecraft," No. AIAA Paper 2008-7869, American Institute of Aeronautics and Astronautics, Reston, VA, 2008.

${ }^{6}$ Brown, O. C., Eremenko, P., and Collopy, P. D., "Value- Centric Design Methodologies for Fractionated Spacecraft: Progress Summary from Phase I of the DARPA System F6 Program," AIAA SPACE 2009 Conference ES Exposition. ${ }^{37}$

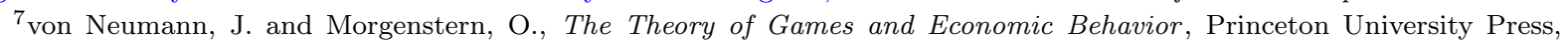
Princeton, 1953.

${ }^{8}$ Collopy, P. D., "Aerospace System Value Models: A Survey and Obsevations," AIAA SPACE 2009 Conference ES Exposition. ${ }^{37}$

${ }^{9}$ Hazelrigg, G. A., "The Cheshire Cat on Engineering Design," QUALITY AND RELIABILITY ENGINEERING INTERNATIONAL, Vol. 25, No. 6, OCT 2009, pp. 759-769. doi:\{10.1002/qre.1028\}.

${ }^{10}$ Collopy, P. "Value-Driven Design Institute Home," [online]. 2009 [cited 03 April 2010].

${ }^{11}$ Rothman, A., \% enquoteEADS Says A380 Jet Is 'Concern as Deliveries Stall, Bloomberg, 16 November 2009.

${ }^{12}$ Collopy, P. and Hollingsworth, P., "Value-Driven Design," 9th AIAA Aviation Technology, Integration, and Operations (ATIO) Conference, AIAA, Hilton Head, SC, 21-23 September 2009. 
${ }^{13}$ Collopy, P. D., "Surplus Value in Propulsion System Design Optimization," 33rd AIAA/ASME/SAE/ASEE Joint Propulsion Conference and Exhibit, No. 97-3159, Seattle, WA, July 6-9 1997.

${ }^{14}$ Doganis, R., Flying Off Course (The Economics of International Airlines), Harper Collins Academic, London, 2nd ed., 1991.

${ }^{15}$ Oum, T. H., Zhang, A., and Zhang, Y., "Inter-Firm Rivalry and Firm Specific Price Elasticities in Deregulated Markets," Journal of Transport Economics and Policy, May 1993, pp. 171-192.

${ }^{16}$ Fridstrom, L. and Thune-Larsen, H., "An Econometric Air Travel Demand Model for the Entire Conventional Domestic Network: The Case of Norway," Transportation Research, Vol. 17A, 1983, pp. 385-393.

${ }^{17}$ Brons, M., Pels, E., Nijkamp, P., and Rietveld, P., "Price Elasticities of Demand for Passenger Air Travel: A MetaAnalysis," Journal of Air Transport Management, Vol. 8, 2002, pp. 165-175.

${ }^{18}$ Ghobrial, A. and Kanafani, A., "Quality of Service Model of Inter-City Air Travel Demand," Journal of Transportation Engineering, 1995, pp. 135-140.

${ }^{19}$ Jorge-Calderon, J., "A Demand Model for Scheduled Airline Services on International European Routes," Journal of Air Transport Management, Vol. 3, No. 1, 1997, pp. 23-35.

${ }^{20}$ Proussaloglou, K. and Koppelman, F., "Air Carrier Demand: An Analysis of Market Share Determinants," Transportation, Vol. 22, No. 4, 1994, pp. 371-388.

${ }^{21}$ Holloway, S., Straight and Level: Practical Airline Economics, Ashgate Publishing, London, 2003.

${ }^{22}$ Kawai, R., "Quiet Cruise-Efficient Short Take-OFf and Landing Subsonic Transport System," NASA/CR 2008-215141, Boeing Technology/Phantom Works, Huntington Beach, CA, April 2008.

${ }^{23}$ Hahn, A. S., oteA Conceptual Design for a Short Takeoff and Landing Regional Jet Airliner, 48th AIAA Aerospace Sciences Meeting Including The New Horizons Forum and Aerospace Exposition, No. AIAA-2010-1011, American Institute of Aeronautics and Astronautics, Orlando, FL, 4-7 January 2010.

24 "Newark Libarty International Airport: Airport Diagram," [online]. 29 July 2010 [cited 29 July 2010].

25 "Laguardia NY: Airport Diagram," [online]. 29 July 2010.

26 "Detroit Metropolitan Wayne County: Airport Diagram," [online]. 29 July 2010.

27 "Airport Capacity Benchmark Report 2004," Tech. rep., Federal Aviation Administration, Washington, DC, September 2004.

${ }^{28}$ nquoteLos Angeles, CA Kerosene-Type Jet Fuel Spot Price FOB, [online]. July 2010 [cited 21 July 2010].

29 "Air Navigation Service Charges," AIP Gen 4-2-1, UK Civil Aviation Authority, 5 July 2007.

${ }^{30}$ quoteManchester Airport PLC: Schedule of Charges and Terms and Conditions of Use 1 April 2010 to 31 March 2011 , Conditions of use, Manchester Airport PLC, Manchester, M90 1QX, United Kingdom, 12 March 2010.

${ }^{31}$ Couluris, G. J., Hange, C. E., Wardwell, D. A., Signor, D., and Phillips, J., "A Potential Impact Analysis of ESTOL Aircraft Operations on Newark Airport Operations," AIAA Modeling and Simulation Technologies Conference and Exhibit, AIAA, Hilton Head, SC, 20-23 August 2007.

32 "On-Time Performance - Flight Delays at a Glance," [online]. August 2010 [cited 24 August 2010].

33 "Air Carriers T-100 Segment (All Carriers) Database," [online]. July 2009 [cited 24 August 2010].

34 "Detailed Arrival Statistics, Newark Liberty International Airport," [online]. July 2009 [cited 24 August 2010].

${ }^{35}$ Adrangi, B. and Raffiee, K., "New evidence on fare and income elasticity of the U.S. airline industry," Atlantic Economic Journal, Vol. 28, 2000, pp. 493-493, 10.1007/BF02298404.

${ }^{36}$ Kim, J. H., Price Dispersion in the Airline Industry: The Effect of Industry Elasticity and Cross-Price Elasticity, Ph.D. thesis, Texas A\&M University, College Station, TX, August 2006.

${ }^{37}$ AIAA SPACE 2009 Conference 83 Exposition, Pasadena, CA, 14-17 September 2009, American Institute of Aeronautics and Astronautics. 